patients were treated with concurrent chemoradiation followed by brachytherapy. The median follow-up period was 47 months. The three-year DFS and OS were $13.3 \%$ and $13.3 \%$ respectively.

Conclusion CCCC has a poor prognosis, stage for stage compared to other histologies. The FIGO stage, tumour size, lymphovascular space invasion and pelvic node status were factors that predicted the prognosis. Adjuvant radiotherapy or chemoradiotherapy have a limited role in the treatment of this rare cancer.

Disclosures The authors have no potential conflict of interest to disclose.

\section{EFFICACY OF A MULTI-INGREDIENT CORIOLUS VERSICOLOR-BASED VAGINAL GEL IN HPV+ WOMEN OLDER THAN 40 YEARS: SUB-ANALYSIS OF PALOMA CLINICAL TRIAL}

${ }^{1}$ Yann Gaslain, ${ }^{2}$ Luis Serrano, ${ }^{3}$ Andrés Carlos López, ${ }^{2}$ Silvia González, ${ }^{4}$ Santiago Palacios, ${ }^{5}$ Damian Dexeus, ${ }^{6}$ Pluvio Coronado, ${ }^{7}$ Jesús de la Fuente, ${ }^{8}$ José Antonio López, ${ }^{9}$ Cristina Vanrell. ${ }^{1}$ Procare Health; ${ }^{2}$ Centro Médico Gabinete Velázquez; ${ }^{3}$ Hospital Quironsalud; ${ }^{4}$ Instituto Palacios Salud Y Medicina de la Mujer; ${ }^{5}$ Women's Health Institute; ${ }^{6}$ Hospital Clínico San Carlos; ${ }^{7}$ Hospital Universitario Infanta Leonor; ${ }^{8}$ Hospital General Universitario de Alicante; ${ }^{9}$ Hospital de la Santa Creu I Sant Pau

\subsection{6/ijgc-2020-ESGO.19}

Introduction/Background HPV clearance and resolution of cervical HPV-dependent lesions become difficult in peri and postmenopausal women. The objective of this sub-analysis was to evaluate the effect of the Papilocare ${ }^{\circledR}$, a multi-ingredient Coriolus versicolor-based vaginal gel, on the normalization of cervical HPV-dependent atypia (ASCUS and LSIL) and associated colposcopic alterations in women older than 40 years.

Methodology Paloma clinical trial (ClinicalTrials. gov NCT04002154) was a multicenter, randomized, open-label, parallel-group, usual practice-controlled clinical trial. Unvaccinated HPV positive women aged between 30-65 with cytology of ASCUS or LSIL and concordant colposcopic image were randomized into 3 groups: A) Papilocare ${ }^{\circledR} 1$ cannula/ day for 1 month +1 cannula/alternate days for 5 months; B) Papilocare ${ }^{\circledR} 1$ cannula/day for 3 months +1 cannula/ alternate days for 3 months; C) Control group: no treatment (usual clinical practice). Primary endpoint:\% of patients with normal cytology and concordant colposcopy after 6 months of treatment in the total population, high-risk HPV $(16,18,31,33,35,39,45,51,52,56,58,59,68)$ and very high-risk HPV (patients infected by any combination of 16, 18 and 31) subpopulations. Pap smear evaluations were blind and centrally conducted by an independent researcher at the IECM laboratory (Lugo, Spain). Papilocare ${ }^{\circledR}$ arms (A+B) were combined as treatment group.

Results A total of 41 out of 84 evaluated patients included in Paloma trial were older than 40y [mean (SD) age: 47.71 (5.56)], of which 30 and 13 were high-risk HPV and 16-18$31 \mathrm{HPV}$ patients, respectively. At 6 months, normal cytology and concordant colposcopic image was observed in 92\%, 90\% and $75 \%$ of patients treated with Papilocare ${ }^{\circledR}$ vs $50 \%, 33 \%$ and $40 \%$ of patients in control group, in the total population, and high-risk and 16-18-31 subpopulations $(\mathrm{p}=0.0066$; $\mathrm{p}=0.0031 ; \mathrm{p}=0.2929$, Fisher test) respectively.
Conclusion Papilocare ${ }^{\circledR}$ showed a robust efficacy in normalizing cervical HPV lesions in women older than 40 years old, with a statistically significant difference vs control group in the total and high-risk populations.

Disclosures

Funding Procare Health Disclosure: J.Cortés, S.Palacios, D. Dexeus, L. Serrano: Advisory/Consulting Role and Speakers at Procare Health. Y. Gaslain: CEO of Procare Health.

All other authors have declared no conflicts of interest.

\section{REAL-LIFE EFFICACY OF A MULTI-INGREDIENT CORIOLUS VERSICOLOR-BASED VAGINAL GEL IN HIGH- RISK HPV PATIENTS: INTERIM ANALYSIS}

${ }^{1}$ Yann Gaslain, ${ }^{2}$ Javier Cortés, ${ }^{3}$ Javier de Santiago, ${ }^{4}$ María Pilar Sanjuán, ${ }^{5}$ Marta Agenjo, ${ }^{2}$ Gabriel Fiol, ${ }^{6}$ Carmen Garcia, ${ }^{7}$ Marta Gurrea, ${ }^{2}$ Perla Hernández. ${ }^{1}$ Procare Health; ${ }^{2}$ Private Practice; ${ }^{3}$ Centro Oncológico MD Anderson; ${ }^{4}$ Clínica Ginemed; ${ }^{5}$ Hospital Sanitas La Zarzuela; ${ }^{6} \mathrm{Hm}$ San Francisco; ${ }^{7} \mathrm{Hospital}$ La Fe

\subsection{6/ijgc-2020-ESG0.20}

Introduction/Background Real-life studies inform on the 'effectiveness' of a treatment what is intended to do in routine circumstances. The aim of this study is to evaluate the efficacy of Papilocare ${ }^{\circledR}$ - a multi-ingredient Coriolus versicolor-based vaginal gel- on repairing high-risk (HR) HPV-dependent lowdegree cervical lesions and HR-HPV clearance in real-life practice.

Methodology Observational, multicenter, prospective, onecohort study (PAPILOBS study ClinicalTrial.gov: NCT04199260). Currently recruiting 300 vaccinated or not HPV-positive women aged $>25 \mathrm{y}$ with Pap smear of ASCUS or LSIL and concordant colposcopy during routine clinical visits in Spain. Patients are treated with Papilocare ${ }^{\circledR} 1$ cannula/ day for 21 days the first month +1 cannula/alternate days for 5 months. After this 6-month period, patients with altered cytology and/or HPV persistency are treated for a 6-month extension treatment period with the same dosage.

Interim analysis of HR-HPV patients with normal Pap smear and concordant colposcopy image (primary endpoint) and patient with HR-HPV cleared (patients with total clearance or partial clearance together with negative Pap smear and normal colposcopy) at $6 / 12$ months is presented. The study was approved by the ethical committee of Public University Hospital of Puerta de Hierro (Madrid). Informed consent was signed by all patients.

Results At 6 months, data of 148 and 146 patients for Pap smear/colposcopy and HR-HPV presence, respectively, were available. $67.6 \%$ of patients $(100 / 148)$ had negative Pap smear and concordant colposcopy. HR-HPV clearance was observed in $58.9 \%$ of patients $(86 / 146)$. Data of 46 and 44 patients included in the 6-month extension treatment period for Pap smear/colposcopy and HR-HPV presence, respectively, were available. At 12 months, 78.3\% (36/46) of patients had negative Pap smear and concordant colposcopy and HR-HPV clearance was observed in $70.5 \%$ (31/44). Considering all study period, $77 \%(114 / 148)$ and $72.6 \%(106 / 146)$ of patients repaired HR-HPV-dependent cervical lesions and cleared HRHPV, respectively.

Conclusion In this interim analysis, repairing of HR-HPVdependent low-degree cervical lesions and clearing HR-HPV, in real life conditions, was achieved after 6-month treatment 